\title{
The Effects of Lexical Chunks Teaching on EFL Intermediate Learners' Speaking Fluency
}

\author{
Mohammad Mohammadi \\ Asst. Prof., Pardis-e-Daneshgahi-e-Daneshgah-e Urmia, Urmia University, Iran, \\ mohammadimohammaduk@gmail.com
}

\section{Bayez Enayati}

$\mathrm{PhD}$ Candidate in English Teaching,Pardis-e-Daneshgahi-e-Daneshgah-e Urmia, Urmia University, Iran, bayezenayati@gmail.com

The present study aimed at investigating the effects of learning lexical chunks on the speaking fluency of EFL Iranian learners (between the ages of 13 and 17) and at the same time taking into consideration the examining participants' use of lexical chunks and their knowledge of them. To this end, after administrating the Quick Placement Test (QPT), 60 intermediate L2 learners were selected at random out of 120 , and then assigned to two experimental and control groups. The learners were assigned an interview of ten questions as a pretest. After that some lessons of lexical chunks using (Collocation in Use and Common Idioms in English) books were thought as the treatment to the experimental group. After the instruction, an interview was conducted on both the experimental and control group as the post test. The T-test analyzed data of the post test revealed that after the treatment, the participants' fluency in the experimental group was significantly improved. The results also showed that the participants in the experimental group had positive attitudes toward explicit instruction of lexical chunks. The study has theoretical and pedagogical implications in the field of foreign/second language teaching and learning.

Keywords: lexical, chunks, intermediate, learners, speaking, fluency

\section{INTRODUCTION}

Fluency in speaking or the ability to speak quickly and easily in English language is the ideal goal for many English learners who wish to learn to communicate through speaking or those who aim to arm themselves with a good knowledge of this skill both for academic and other purposes. Non-native speakers often strive hard to achieve a native-like fluency. Learning how to speak fluently is still a problem for many EFL learners, although they spend a lot of time and invest a lot of money on learning English in different institutes, schools, universities, etc. Learners may fulfil the course 
requirements but they often fail to cope with the requirements in order to have a fluent speech. As pointed out above, the reason might be due to their lack of understanding of what chunks in English language are.

Learners in EFL settings typically often have problem of lacking exposure to the target language and consequently, they are often not aware of the differences in lexical chunks between the L1 and the L2. Questing scholarly for the reasons of lack of proficiency in speaking, I came across researchers such as Richards (2008) who claims that when carrying out communication tasks, low-level students often rely on a lexicalized system of communication that depends heavily on vocabulary and memorized chunks of language. Besides, Lackman (2008) argues that lexical approach in which chunks play a vital role does not exclude the grammar and structural nature of language. Similarly, Wilkins states that we can express little without grammar, but nothing can be conveyed without vocabulary (Wilkins, 1972). As the pioneers of the Lexical approach, Richards and Rodgers (2001) state that the building blocks of language learning and communication are not grammar, function, notions, or some other unit of planning and teaching but lexis, i.e., word and word combinations. Pawley and Syder (1983) suggest that native speakers have a repertoire of thousands of routines, or "chunks," like these. Their use in appropriate situations creates conversational discourse that sounds natural and native-like, so they have to be learned and used as fixed expressions. Accordingly Prodromou (2007) suggests that a key difference between the speech of advanced successful users of English (SUEs) and native speakers is the presence or absence of chunks. In addition, a number of researchers pointed out that to learn a wide and varied vocabulary of individual words, English learners must also cope with a great number of multiword units (Moon, 1997, 1998; Wray, 2000).

Today scholars share the same consensus regarding the prevalence of chunks in language production (see Ketko 2000, Lind Stromberg, 2009 and ...). For example, Ketko (2000) addresses the crucial role of multi-word chunks in facilitating communicative competence. Accordingly, Richards (2008) holds that there are many factors that can contribute to the naturalness of speech and points out that one important factor is the extent to which the learners are using what are sometimes called multi-word chunks, as well as conversational routines or fixed expressions.

Focusing on bottom-up processing Jack C. Richards (2008) believes that the chunks help us identify the underlying propositions the utterances express. In his article "Teaching listening and speaking, from theory to practice", he points out that we have to break some utterances down into their components in order to understand them. $\mathrm{He}$ called this process "chunking". If formulaic chunks play a large role in early language acquisition, it may pay to focus on these initially, delaying the teaching of grammar until later, as proposed by Ellis (2002). Referring to the widespread benefits of using chunks in EFL classes, in the present paper, I aim to focus on these prefabricated units of language in order to measure their impact on speaking in general, and on fluency in particular. 


\section{Review of the Related Literature}

In the much of the traditional literature on Formal and theoretical Linguistics, lexical chunks have received relatively little attention. Most of lexical chunks' biggest proponents are coming from the areas of Applied Linguistics and Education, specifically Foreign Language Education. Being a difficult phenomenon to pin down formally makes one of the reasons of lack of discussion of lexical chunks in Formal Linguistics. Lexical chunks do not fit neatly into traditional linguistic categories since they combine semantic, syntactic, lexical, and even pragmatic information. Another reason for lack of discussion of lexical chunks in formal linguistics is that they are difficult to define in simple, universally applicable terms. . Despite this, some efforts have been made, and in the following I will review some of the most influential studies related to the current study.

In an effort to find the effects of lexical chunks on writing Qian Li (2014) carried out an empirical study on the application of lexical chunks to college English writing in Jiaotong University, Jinan, China. The research question was whether the application of lexical chunk approach to EFL teaching helps to improve college students' EFL writing level. After the treatment the results proved the fact that the lexical chunk teaching and learning approach plays a positive role in improving the college students' English writing.

Similarly Ranjbar, N. et al. (2012) attempted to investigate the effects of lexical bundles on Iranian EFL learners' paragraph writing production fluency. To achieve this purpose, they administrated an English language proficiency test to 120 language learners studying TEFL at Islamic Azad University of Dehloran and ultimately they selected 90 language learners and divided them into two groups of control and experimental groups, based on their proficiency test scores. The findings of their study showed that lexical bundles instruction could bring a significant change in the experimental group learners since they received instruction on lexical bundles.

Research on chunks is based on the assumption that native speakers use plenty of chunks in their every day language and they are considered as fluent speakers of language (McCarty \& Carter, 2002; Boers et al., 2006; Conklin \& Schmitt, 2008). The findings of Zafarghandi, et al. (2017) were along with what McCarty and Carter (2002) stated about the implications of multi word strings (chunks) for the notion of fluency. Their research on using chunks in the classroom showed that mastery of ready made chunks could help learners to develop their fluency in speaking English. On the other hand the participants in Zafarghandi and his colleagues' study were made aware of the advantages of using chunks in their speech and they were encouraged to use them while speaking throughout the whole semester.

Movahediyan Attar and Allami (2013) investigated the effect of teaching collocations on the speaking ability of EFL Iranian learners and at the same time tried to examine the relationship between the participant's knowledge of collocations and also their use of collocations. They also made an attempt to find out their attitude towards teaching collocations. The results of their research revealed that teaching lexical collocation was a useful mean to maximize collocation knowledge. They further mentioned that learners 
could manage to have more control over speaking ability in English and comprehend the ideas within the dialogues and conversations after having being taught the collocations.

Regarding the relationship between lexical bundles and linguistic production fluency, Pawley and Syder(1983), Nattinger and DeCarico (1992), and Wood (2001), lexical bundles and formulaic language units help second language learners to increase their speech speed by building sentences and increasing the length of their speech. These authors believed that if learners memorized a large amount of bundles and automatically retrieve them, they can gain a native like fluency and increase the length of the speech between pauses.

The current study would examine the Iranian EFL context in terms of teenage learners' lexical competence and the variables contributing to its development and use. Following the recommendation given by Chun-Guang, T.(2014), the current study would attempt to confirm whether EFL learners' speaking is influenced by their LG(lexical chunks) competence. To date, as far as I revised the literature, no comprehensive research has investigated how EFL learners' processing strategies for learning, memorizing and automatizing lexical chunks can account for their speaking fluency problems.

\section{Problem of the Study}

The researchers, being an instructor of speaking skill, noticed that EFL learners at Shahab English Institute, especially teenagers, face a difficulty in speaking skill. This difficulty emerges from the fact that most of them are not used to speaking English at schools. Most of them confront difficulty in organizing ideas, using correct structure, employing English speaking styles, and finding suitable vocabulary to express their ideas.

\section{Questions of the Study}

1. Does lexical chunks instruction have any significant on Iranian EFL learners' speaking fluency?

2. Is there any significant difference between experimental and control group mean scores on the post-test after the treatment?

\section{Variables of the Study}

The variables of the present study include lexical chunks learning ( independent variable) and speaking fluency( dependent variable).

\section{Definitions of the terms}

In this study, speaking fluency indicates the number of words, regardless of repeated ones, in a T-unit. Lexical chunks fall into ten types of words, poly-words, collocations, fixed expressions, semi-fixed expressions, compounds, phrasal verbs, idioms, fixed phrases and prefabs. (Lewis, 1997:8, Moon, 1997)

\section{Purpose of the Study}

This study aims to investigate the degree of impact of learning lexical chunks, which is implemented in the classroom as an extracurricular activity, on the development of speaking fluency in terms of increasing the number of words per T-units in the participants' oral speech. 


\section{Significance of the Study}

The significance of the present study emerges from the belief that it hopefully provides experimental evidence and support to the proposition that lexical chunks learning may improve the EFL learners' speaking fluency through reading-speaking connection activities and help them overcome some of the difficulties they may face specifically when speaking fluency is emphasized.

\section{METHOD}

This study was an attempt to determine the possible effects of teaching lexical chunks on the speaking fluency of EFL Iranian learners and at the same time taking into consideration the examining participants' use of lexical chunks and their knowledge in them. The research design was experimental. To achieve this success, two groups (control and experimental) design was employed for the study. A typical experimental study usually uses comparison or control groups to investigate research questions. This is known as a between - groups design. (Mackey \& Gass, 2005, 146) Using Test of English as a Foreign Language (TOEFL) as a measure for their proficiency in English, the subjects were randomly assigned into two groups (experimental and control) in random. The experimental group was given the treatment. During the treatment the experimental group utilized lexical chunks and wrote so many unified paragraphs about different topics and then they presented them in the class and discussed them. They were asked to make use of lexical chunks in their conversations. Finally they played the role of the provided conversations in the classroom. The learners in the control group did not receive any instruction on lexical chunks. They just received placebo. They studied the same text-book (Headway) through the conventional method of language teaching, grammar translation method with no instruction on lexical chunks.

\section{Participants}

In the present research the intermediate level participants of Shahab English Institute in Mahabad were selected through availability sampling method since the other English institutes in Mahabad did not devote any time for research according to the limitations they had. To this aim the researcher carried out a Quick Oxford Placement Test (QOP) of 60 questions in order to homogenize the participants and select the intermediate level participants. Then 60 participants out of 140 were chosen through random selection in order to participate in the study. The selected participants were divided into two groups of 30 students. They shared the characteristics below:

1. The majority of them studied at public schools before attending the institute. They were all Iranian learners with intermediate non-native English levels.

2. All the selected learners were of the same gender.

3. Both groups of the students were studying American Headway 3 as the institute obligatory book with the same instructor and also the same class time on different days.

4. Their ages ranged from 12 to 17 with the mean age of 15 .

5. They are taught Headway Serious books as the obligatory books. 


\section{Instrumentation}

The instruments of the present study were QPT (Quick Proficiency Test), a test of collocations and a collocation interview. The first instrument of the present study was QPT (Quick Proficiency Test), version 1, consisting of two parts, which was used to homogenize the participants and be assured of their level. The first part included 40 questions while in the second one there were 20 questions. It was necessary for the participants to get a score between one standard deviation above and below the mean in order to take part in the study.

The second instrument was a test of lexical chunks which was s used as the pre-test and post-test. It involved 30 multiple choice items and was administrated to all sixty participants in the study with the scores from 0 to 30 . The lexical chunks had been selected from "English Collocations in Use" book, written by Michael McCarthy and Felicity O'Dell. They had been selected according to 18 units of the mentioned book. The reliability of lexical chunks test was already calculated and it was 0.82 , acceptable for such a study.

The third instrument of the study was a ten-minute interview which was used as a pretest and posttest. It consisted of ten open questions by which the participants were able to talk about their main opinions and ideas and support their ideas using the lexical chunks they had already learned in the 18 sessions of study. The test was mainly a production one and the participants had to talk about ten topics using the lexical chunks they had learnt. The inter-rater reliability of the interview was calculated and it was significant for the study.

\section{Procedure}

The aim of the present research was to determine the possible effects of lexical chunks instruction on the speaking fluency of EFL intermediate learners in Iranian contexts. To this aim, all the 140 available EFL learners in Shahab English institute were given QPT (Quick Placement Test) which was consisted of 60 items with 30 vocabulary items and 30 grammar items. This test was given to 140 participants. They had 30 minutes time to answer the questions. The researchers carried out this test to determine the level of the learners and homogenize them. Then, 60 students were selected out of 140 participants. hey were divided into two groups of control and experimental, each consisted of 30 participants. Te researchers pre-tested the selected subjects in both groups (control and experimental). To do so, all the sixty participants were fallen through two pre-tests, including a test of collocation and interview. A 30-item collocation test was given to all the participants. The participants had twenty minutes time to answer questions. They had to fill in the gaps with the correct given collocations. After that all of the participants took part in a interview of 10 questions. The questions took each participant 10 minutes to answer them. After the pre-test, the students in the experimental group were given a treatment. They were taught the collocations in use with some famous lexical chunks on different topics along a period of six weeks that extended from the $1^{\text {st }}$ of September to the $5^{\text {th }}$ of November in 2016. They studied lexical chunks and collocations three sessions of 90 minutes a week. 
In each session the subjects were taught a lesson of Collocations in Use and also ten lexical chunks, mainly fixed expressions and idioms. The experimental group members were acquired to underline the lexical chunks and use them in their own sentences in order to learn them. Each lesson of the book (Collocations in Use, written by Michael McCarthy and Felicity O'Dell) contains some lexical chunks mainly two word verb phrases, adjective plus noun combinations and most common idioms by which the subjects could improve the number of their words in the T-units. Each session the participants were taught a unit and then they were asked to practice the lexical chunks exercises by making example sentences in which those chunks were used. They also had to do the exercises which were the following pages of the same unit. After being taught each lesson, they were asked to read the lessons and underline the collocations and idioms and use them in their own sentences. In the next sessions the instructor would go through the new unit. He used to ask some questions of the previous lessons, too. The instructor would select the units according to their importance and the units including more useful lexical chunks in spoken English were often chosen for teaching. On the other hand the subjects in the control group were only asked to study the course required passages, Headway Book 3, without being asked to study any further extracurricular assignments. After the end of six weeks, the subjects in both groups were post-tested in speaking fluency through an interview on the same topics of the pre-test and a test of collocations similar to the previously carried out in the pre-test but with different lexical chunks and collocations. In the process of the interview, the participants were required to discuss their ideas about ten main issues they may face in their life, Appendix (1). While analysing the participants' post-test transcriptions, the researcher focused on their improvement in terms of speaking fluency through focusing on the number of words in the T-units. Some sample assignments are provided in Appendix (2). The interviews were transcribed and analysed to assess whether or not there were any significant differences between these groups in terms of speaking fluency. There were ten main questions to be asked by the interviewer besides some warm-up questions. Speaking fluency was measured using Freed, et el. (2004) by looking at the number of words per t-units (W/T-unit). After the scores' measurement, the raw scores were analysed by SPSS statistical Software. The researcher used the t-test to estimate the statistical differences in the scores' means in both tests in the two groups. To this end, the raw data was analysed using SPSS statistical software by a statistician. It was also decided to look at the ten types of lexical chunks presented in Lewis (1997) and Moon (1997) listed in Appendix (3).

\section{FINDINGS}

Table (1) shows the two groups' means, Std. Deviations and Std. Error Means of the post -test.

Table 1

Independent Samples T-test Post-test control \& experimental

\begin{tabular}{llccccc}
\hline \multicolumn{5}{c}{ Group Statistics } \\
\hline & Post-Test & $\mathrm{N}$ & Mean & Std. & Deviation & Std. Error Mean \\
\hline Fluency scores & Experimental & 30 & 12.020 & 1.3752 & .2511 \\
\hline & Control & 30 & 10.047 & 1.6854 & .3077 \\
\hline
\end{tabular}


Figure (1) presents the results for speaking fluency in both the experimental and control groups, showing the scores' mean in both groups.

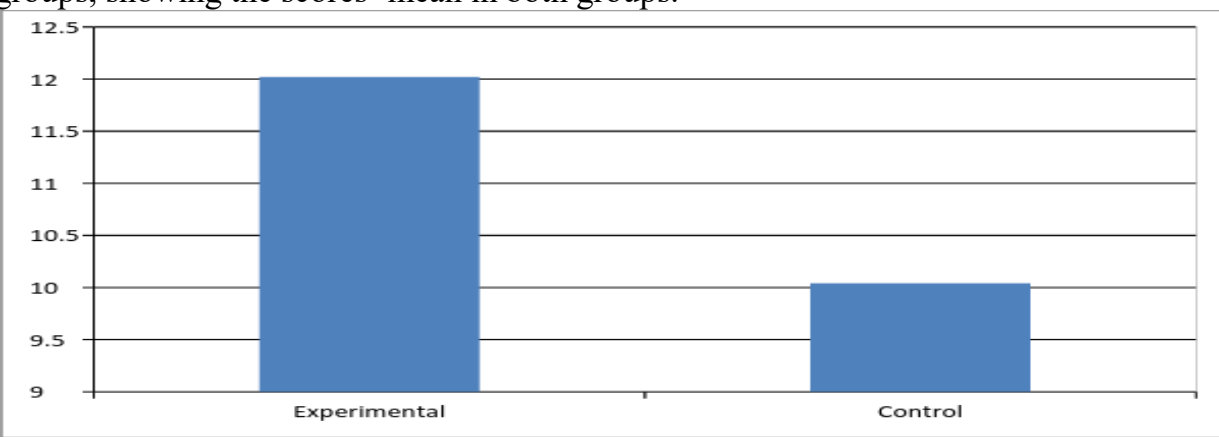

Figure 1

Experimental and Control group scores' mean in the post-test.

Table (2) shows the results of the results of applying independent samples t-test. The results of applying independent samples t-test for comparing the means of the post-tests of experimental and control groups showed that there were significant differences between the performances of the two groups in the post-test.

Table 2

Independent Samples Test

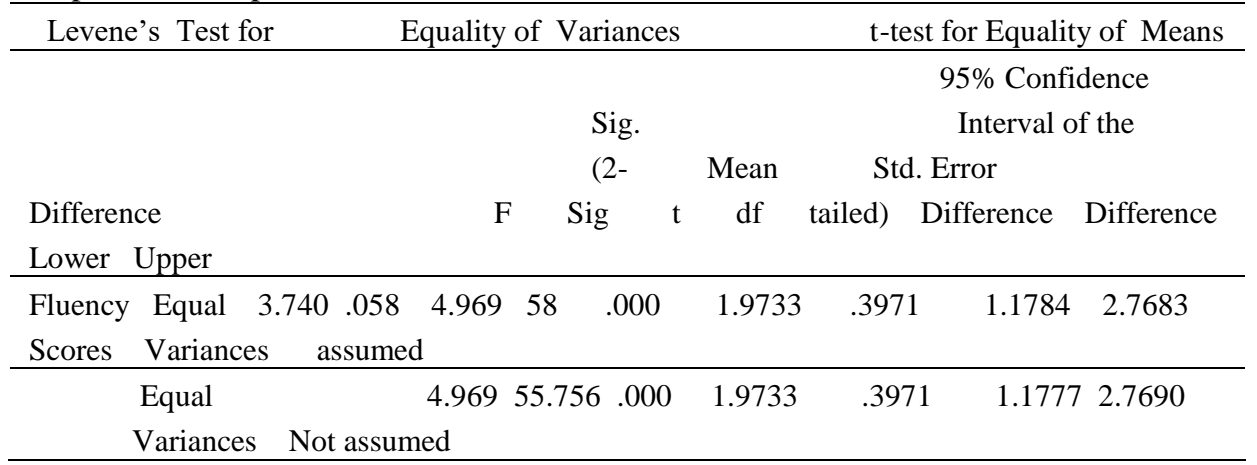

Table (3) presents the results for speaking fluency in the experimental group, showing the scores' means, Std. Deviation and Std. Error Mean.

Table3

Paired Samples Statistics of the Experimental Group in both tests

\begin{tabular}{cccccc}
\hline \multicolumn{5}{c}{ Paired Samples Statistics } \\
\hline & & Mean & $\mathrm{N}$ & Sts. Deviation & Std. Error Mean \\
\hline Pair 1 & Pre-test & 9.980 & 30 & 1.4949 & .2729 \\
\hline & Post-test & 12.020 & 30 & 1.3752 & .2511 \\
\hline
\end{tabular}


The scores' mean in the Experimental group was 9.980 in the pre-test whereas it is 12.020 in the post-test. It shows an increase in the scores' mean after the treatment.

Figure (2) shows the scores' means in the Experimental in both Pre-test and Post-test.

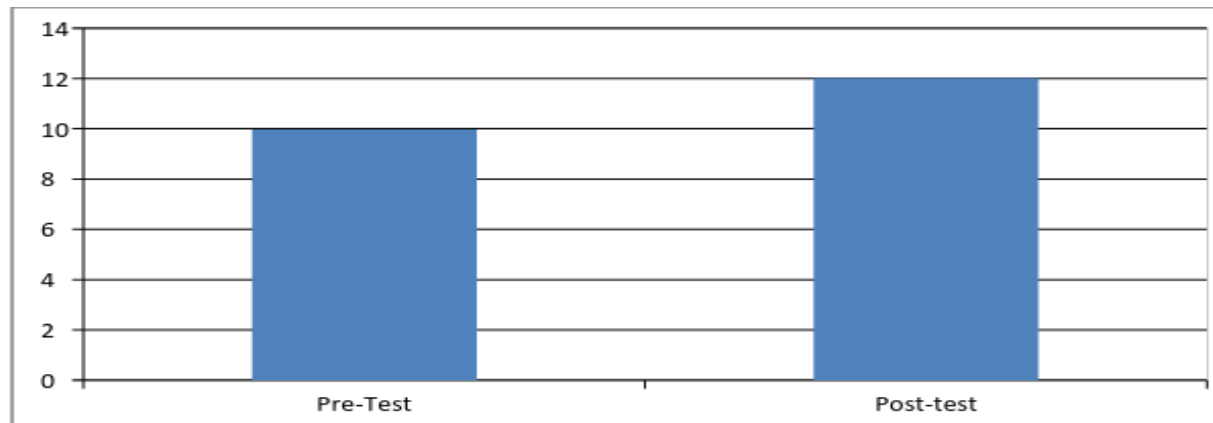

Figure 2

Paired Samples T-test for Experimental group's Pre-test and Post-test

Table (4) presents results of applying paired samples t-test for comparing the means of experimental group learners' pre-test and post-test scores.

Table 4

Paired Samples Test Results for the Experimental Group

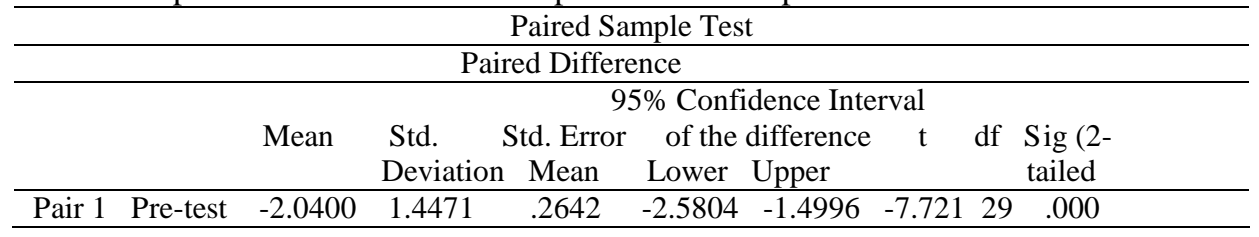

The results of applying paired samples t-test for comparing the means of experimental group learners' pre-test and post-test scores indicated that there were significant differences between the performance of the learners in pre-test and post-test. The mean value of the learners' scores in the experimental group shows an increase in the post test. The difference between the means is statically significant since the level of significance is .000 and it is less than 0.05 , the required sig. (2-tailed) for the two tests' significant results. It is noticed that the speaking fluency of the learners in the experimental group has developed due to the exposure to extracurricular speaking assignments through a period of six weeks $(1 / 9-5 / 11 / 2016)$ during the first fall semester of the institute program in 2016. Appendix (4) and (5) shows each subject's scores in both tests in this group. The difference in scoring between the pre and post tests in the experimental group can be mainly attributed to the fact that subjects in this group were exposed to more quantities of lexical chunks regardless of topics that were read and learnt.

Table (5) summarizes the control group speaking fluency scores. It presents the results for speaking fluency in the control group, showing the scores' means, Std. Deviation and Std. Error Mean. 
Table 5

Paired Samples Statistics of the Control Group in both tests

\begin{tabular}{ccccccc}
\hline \multicolumn{7}{c}{ Paired Samples Statistics } \\
\hline & & Mean & $\mathrm{N}$ & Std. & Deviation & Std. Error Mean \\
\hline Pair & 1 & Pre-test & 10.300 & 30 & 1.6354 & .2986 \\
\hline & & Post-test & 10.047 & 30 & 1.6854 & .3077 \\
\hline
\end{tabular}

The scores' mean in the control group was 10.300 in the pre-test and it is 10.047 in the post-test. It shows no statistically significant difference in the post-test. Figure (3) shows the scores' means in the Control in both Pre-test and Post-test.

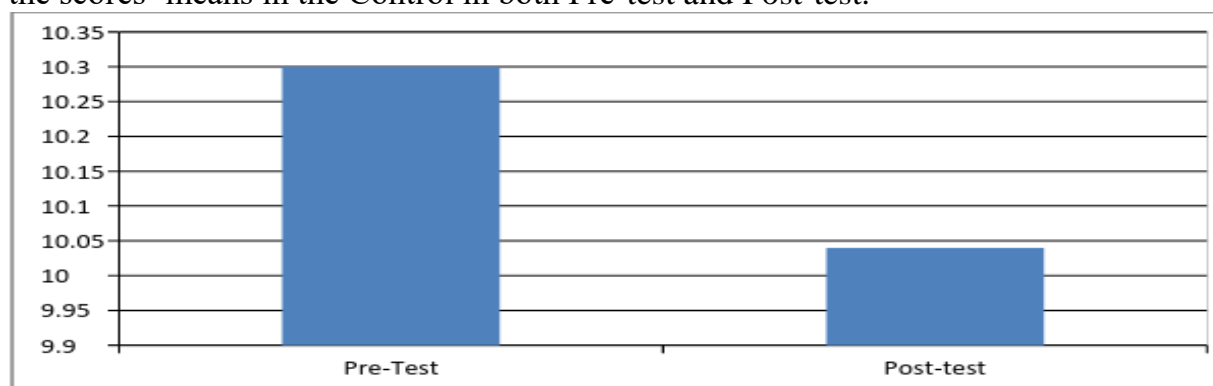

Figure 3

Paired Samples T-test for the Control group's Pre-test and Post-test

Table (6) presents results of applying paired samples t-test for comparing the means of control group learners' pre-test and post-test scores.

Table 6

Paired Samples Test Results for the control Group

\begin{tabular}{|c|c|c|c|c|c|}
\hline \multicolumn{6}{|c|}{ Paired Sample Test } \\
\hline \multicolumn{6}{|c|}{ Paired Difference } \\
\hline & & & $95 \%$ Confidence In & rval & \\
\hline & Mean & $\begin{array}{l}\text { Std. Std. Error } \\
\text { Deviation } \quad \text { Mean }\end{array}$ & $\begin{array}{l}\text { of the difference } \\
\text { Lower Upper }\end{array}$ & $\mathrm{t} \quad \mathrm{df}$ & $\begin{array}{l}\text { Sig }(2- \\
\text { tailed }\end{array}$ \\
\hline Pair 1 Pre-test & .2533 & $\begin{array}{ll}2.3889 & .4361 \\
\end{array}$ & $\begin{array}{ll}.6389 & 1.1454 \\
\end{array}$ & $.581 \quad 29$ & .566 \\
\hline
\end{tabular}

The results of applying paired samples t-test for comparing the means of the control group learners' pre-test and post-test scores indicated that there were not significant differences between the performance of the learners in pre-test and post-test. As you see the level of significance (2-tailed) is .566 and it is more than 0.05 , so there is not a significant difference between the performances in both tests.

\section{DISCUSSION}

The present study set out to investigate two research questions: (1) whether lexical chunks instruction had any significant on Iranian EFL learners' speaking fluency; and (2) whether there is any significant difference between experimental and control group mean scores on the post test after the treatment. In light of the research questions, the most important finding of this study is that lexical chunks instruction could bring a 
significant change in the fluency of the learners in the experimental group since they worked on lexical chunks in different contexts of role play, discussion, paragraph writing and conversation. During the treatment the experimental group utilized lexical chunks and wrote so many unified paragraphs about different topics. Then, they presented them in the class and discussed them. Also, they made use of lexical chunks and wrote conversation around the topics mentioned in their text-book. Finally they played the role of the provided conversations and text-book conversations, too. All these contexts and the received instruction helped learners promote their speaking fluency on the post test. This, in turn, developed the experimental students' paragraph writing fluency which is not discussed in the present paper. This development was due to the instruction and learning large amount of lexical chunks and automatically retrieving them in their paragraph writing and later on in their oral communication. Therefore, instructing Iranian EFL learners in lexical chunks and using them in different contexts promoted their linguistic production fluency. So, the research instruction was considered as an influential method.

As regards the participants in the control group, they did not receive any instruction on lexical chunks. They studied the same text-book (headway) through the conventional method of language teaching, grammar translation method. They received no instruction on lexical chunks. Since they did not work on lexical chunks in different contexts as the experimental group did, their performance on the post test did not change much in comparison to their pre test mean score. Thus, the reason why the experimental and control group participants' performance on the post test was significantly different was due to instruction.

The results of the inferential statistics related to the second question also revealed that the experimental and control group performed significantly different on the post test. That is to say, the experimental group participants who received instruction on lexical chunks did much better than the control group students who did not receive instruction. This stated that there was a significant difference between the mean scores of experimental and control groups. In other words, this difference was due to the improvement of experimental group learners' speaking fluency. This improvement, in turn, was merely due to the instruction. Also, as regards the participants in the control group, they did not do well on the post test in comparison to the experimental group participants. So, they did not show any significant improvement in their speaking fluency. This lack of improvement was due to the fact that they did not receive instruction on lexical chunks. They just received placebo instruction and did not work on chunks in different contexts. So, it was revealed through the results of the inferential statistics that control group participants did not show any improvement on the post test. Thus, the difference between the two groups' mean scores on the post test proved to be significant as the result of lexical chunks instruction.

The results of the present study substantiated the findings of Movahediyan and Allami (2013) that teaching lexical collocations is a useful mean to maximize collocation knowledge and accordingly EFL learners can manage to have more control over speaking ability in English and at the same time comprehend the ideas within the dialogues and conversations through the use of collocation knowledge. 
Similarly the findings of the present study are also in accordance with the theory of Richards (2008) that holds there are many factors that can contribute to the naturalness of speech and that one important factor is the extent to which the learners are using what are sometimes called multi-word chunks, as well as conversational routines or fixed expressions.

Additionally, this study produced results which corroborate the theories of Pawley \& Syder (1983), Nattinger \& DeCarico (1992), and Wood (2001) theorising that lexical bundles and formulaic language units help second language learners to increase their speech speed by building sentences and increasing the length of their speech.

Finally, the researcher came to this conclusion from the current section that lexical chunks had a significant effect on Iranian EFL learners' speaking fluency. Moreover, there was a significant difference between the experimental and control group speaking fluency. Also, all these improvements and difference were due to the instruction of lexical chunks.

\section{CONCLUSION}

The present study examines the development of speaking fluency in EFL learners through the use of reading-into-speaking method via exposure to extracurricular lexical chunks. It examines variations in the learners' speaking performance in term of fluency, which can be one other indications of effective speaking. The results suggest that the reading-into-speaking method or exposure to extensive lexical chunks reading and learning had a positive impact on the speaking fluency development of these learners, who are lower and average intermediate EFL learners.

Speaking fluency of the experimental group was higher than that of the control group. A possible reason for this might be that the learners had more chance of reading and working with lexical chunks in various texts. Thus learning lexical chunks had a major impact on the participants' speaking fluency in the experimental group.

Moreover, exposing EFL learners to a quantity of reading texts of different lexical chunks may contribute in reducing the anxiety of confronting the task of speaking which is considered as the most difficult experience in producing L2. Similarly, learning lexical chunks through reading can decrease the degree of stress during speaking because it offers the L2 speaker the bulk repertoire of vocabulary, structures, idioms, discourse connectors, multi words, verb phrases, stylistic devices, etc. Learners will deal with speaking in a less confused manner due to the fact that they are ready to produce and express their thoughts and feelings through exploiting familiar and relevant vocabulary and grammars derived from the rich source, which is lexical chunk. The study not only indicates the importance of lexical chunks to speaking fluency improvement, but also brings some pedagogical suggestions to English instruction.

It is hoped that these findings will contribute to our understanding of reading/speaking and the adaptation of lexical chunks instruction in EFL contexts. They may be useful for the development of speaking fluency teaching activities that are directed to lower and average intermediate learners or even lower and average level learners in EFL contexts. More specifically, this kind of research may help teachers who teach speaking skill in 
Iranian institutes to recognize the importance of lexical chunks directed speaking tasks in the EFL speaking classroom, as the results point to the positive impact of lexical chunks on the development of students' speaking fluency.

So we can make a conclusion that learners' speaking fluency can be improved by the application of Lexical Chunk Approach to EFL teaching. According to the grading criteria of EFL speaking fluency, the scores should be marked based on the expressions of the number of words per T-units. . Therefore, the use of the vocabulary and phrases is fundamental to the marking of the speaking fluency. The application of Lexical Chunk Approach to EFL teaching helps to store the ready-made lexical units into the learners' mind, which benefits the appropriate language production for a particular situation.

In addition to the score analysis, the teachers pay more attention to the students' lexical use in their expressions. It is found that lexical chunks help students to use English fluently and properly. Besides, the input of lexical chunks as a whole can avoid errors resulting from vocabulary selection and cultural differences, thus improving the accuracy of language. With lexical chunks in mind, students can speak more fluently, which reduces their anxiety during the process of speaking and increases their confidence. After the application of lexical chunk for one term, it is observed that students' EFL speaking fluency has improved a lot.

\section{REFERENCES}

Boers, F.; Eyckmans, J.; Kappel, J.; Stengers, H. \& Demecheleer, M. (2006). Formulaic Sequences and Perceived Oral Proficiency: Putting a Lexical Approach to the Test.

Language Teaching Research, 10/3, 245-261.

Chunguang,T.(2014). An empirical Research on the Corpus-driven Lexical chunks Instruction. International Journal of English Language Teaching, 2/2, 1- 36.

Conkin, K. \& Schmit, N.(2008). Formulaic Sequences: Are They Processed More Quickly than Non-formulaic Language by Native and Non-native Speakers? Journal of Applied Linguistics, 29/1, 72-89.

Ellis, N. (2002). Frequency Effects in Language Processing: A Review with Implications for Theories of Implicit and Explicit Language Acquisition. Journal of Studies in Second Language Acquisition, 24.

Frank, B. \& Lindstromberg, S. (2009).Optimizing a Lexical Approach to Instructed Second Language. Palgrave-Macmillan, 36.

Freed, B.; Segalowitz, N., \& Dewey D. (2004). Context of Learning and Second Language Fluency in French: Comparing Regular Classroom, Study Abroad, and Intensive Domestic Immersion Programs. Studies in Second Language Acquisition, 26, 275-301.

Ketko, H. (2000). The Importance of Multiword Chunks in Facilitating Communicative Competence and their Pedagogic Implications. Language Teacher Online 24/12. Retrieved 11/ 12/02 from the World Wide Web: http://www.langue.hyper.chubu.ac.jp/ jalt/ pub/ttt/00/dec/ ketko.html>. 
Krishnamurthy, R. (2012). Language as Chunks, not Words. International Journal on Applied Linguistics, 20-25.

Lackman, K. (2011).Teaching Collocations: Activities for vocabulary Building. Ken Lackman \& Associates Educational Consultants.

Lewis, M. (1997).Pedagogical Implications of the Lexical Approach in Coady, J. \& Hockin, J. (Eds). Second Language. Cambridge: Cambridge University Press, 8.

Li, Q. (2014).An Empirical Study on the Application of Lexical Chunks to College English Writing. Journal of Language Teaching and Research, 5/3, 682-688.

Mackey, A. \& Gass, S.M. (2005). Second Language Research: Methodology and Design. Published by: Lawrence Erlbaum Associates, Inc, 146.

McCarthy, M. \& Carter, R. (2002). This, that and the Other: Multiword Clusters in Spoken English as Visible Patterns of Interaction. The Irish Yearbook of Applied Linguistics, 21, 30-52.

Moon, R. (1997). Vocabulary Connections: Mufti-word Items in English, In N. Schmitt and M. McCarthy (Eds): Vocabulary, Description, Acquisition and Pedagogy. Cambridge: Cambridge University Press, 43.

Movahediyan Attar, E. \& Allami, H. (2013). The Effects of Teaching Lexical Collocations on Speaking Ability of Iranian EFL Learners: Theory and Practice in Language Studies, 3/6, 1070-1079

Nattinger, J. \& Decarrico, J. (1992).Lexical Phrases Teaching. Oxford: Oxford University Press, and Language.

Pawley, A. \& Syder, F.H. (1983). Two Puzzles for Linguistic Theory: Nativelike Selection and Nativelike Fluency. In Richards J.C. \& Schmidt, R.W. . Language and Communication. London: Longman, 191-225.

Prodromou, L. (2007). Bumping into Creative Idiomaticity, English Today, 89, 14-25.

Ranjbar, N.; Pazhakh, A. \& Gorjian, B. (2012). The Effect of Lexical Bundles on Iranian EFL Learners' Linguistic Production Fluency, Canadian Centre of Science and Education, 1-9.

Richards, J.C. (2008). Teaching Listening and Speaking: from Theory to Practice. Cambridge University Press, 19-28.

Richards, J. C. \& Rodgers, T S. (2001). Approaches and Methods in Language Teaching. ( $2^{\text {nd }}$ edition) Cambridge: Cambridge University Press, 23.

Wilkins, D. (1972). Linguistics in Language Teaching, London: Arnold,111.

Wood, D. (2001). In Search of Fluency: What is it and how can we teach it? Canadian Modern Language Review, 57 (4), 573-589.

Wray, A. (2000) Formulaic Sequences in Second Language Teaching: Principle and Practice. Journal of Applied Linguistics, 21/4, 463-489.

Zafarghandi, A. \& Emamzesh, S. (2018). The Effect of Teaching Lexical Collocations on Iranian Learners' Writing Ability: Focusing on the Appropriate Use of Collocations. Journal of Applied Linguistics and Language Research.3/5, 107-117. 